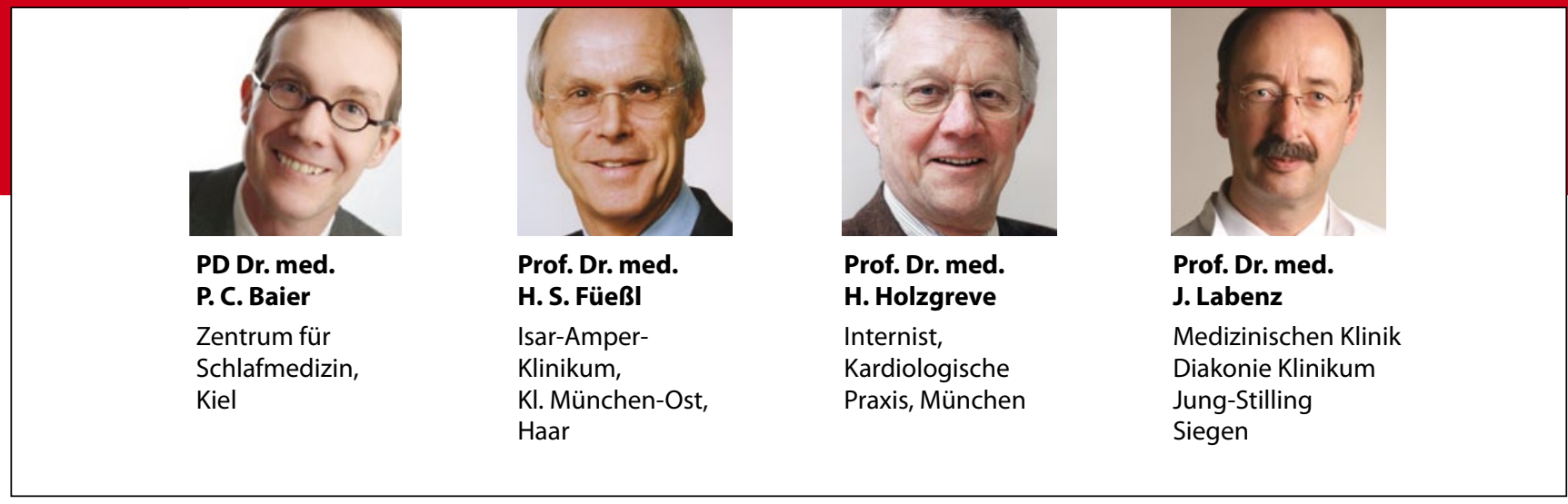

\title{
Koffein schützt vor Unfällen bei langen Autofahrten
}

\section{LKW-Fahrer, die auf langen Fahrten Koffein zu sich nehmen, sind seltener in Unfälle verwickelt.}

- In dieser Fall-Kontroll-Studie aus Australien wurden verglichen: als Fälle 530 LKW-Fahrer, die auf Fahrten über mindestens $200 \mathrm{~km}$ einen polizeilich registrierten Unfall hatten, und als Kontrollen 517 vergleichbare Berufskraftfahrer ohne Unfall, die an Rastplätzen rekrutiert wurden. Vertraulichkeit und
Anonymisierung der Daten wurden zugesichert, eine Schlafapnoe ausgeschlossen. Erfahrene Interviewer fragten nach Konsum von koffeinhaltigen Getränken wie Kaffee, Tee, Energiegetränken oder Koffeintabletten zur Erhöhung der Wachsamkeit bei den Fahrten. Zusätzlich wurden auch zahlreiche Informationen über persönliche und gesundheitliche Faktoren abgefragt.

Unter allen Probanden nahmen 43\% Koffein zu sich, um auf den Fahrten wa- cher zu bleiben. Nur 3\% nahmen illegale Drogen wie Amphetamine, Ecstasy oder Kokain. Nach Berücksichtigung zahlreicher möglicher Einflussfaktoren hatten Fahrer, die Koffein konsumierten, in den zurückliegenden fünf Jahren ein um $63 \%$ niedrigeres Risiko für einen Unfall.

\section{- L. N. Sharwood et al.}

Use of caffeinated substances and risk of crashes in long distance drivers of commercial vehicles: case-control study. Brit. Med. J. 2013; 346: f1136

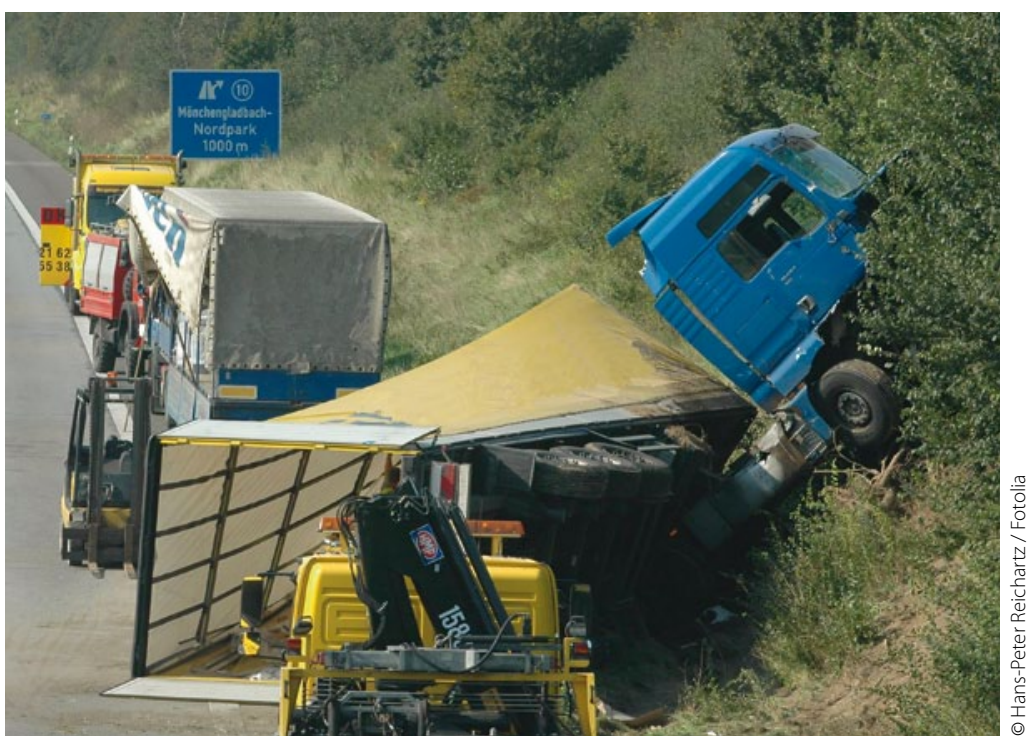

Kaffee reduziert das Unfallrisiko bei Kraftfahrern signifikant.

\section{Kommentar}

Koffein ist ein weit verbreitetes Psychostimulans. Studien im Labor und im Fahrsimulator haben bereits gezeigt, dass seine Einnahme die Wachsamkeit und Aufmerksamkeit bei monotonen Tätigkeiten erhöht. Lange Autofahrten sind monoton und ermüdend, manchmal auch mit Schlafentzug und Beeinträchtigung des zirkadianen Rhythmus verbunden. Diese Untersuchung bestätigt andere Vorbefunde und zeigt, dass die Einnahme von legalen Stimulanzien wie Koffein - natürlich im Verbund mit anderen Strategien wie Limitierung der Fahrzeiten und regelmäßige Pausen - die Unfallgefahr bei kommerziellen LKW-Fernfahrten verringert. Auch wer privat mit dem PKW weite Strecken fährt, sollte - auch ohne gesetzliche Vorschriften wie für Berufskraftfahrer - mal anhalten, sich bewegen, ein Nickerchen machen oder auch eine Tasse Kaffee trinken.

H. HOLZGREVE = 